The Implementation of an Electronic Health Record: Comparing Preparations for Epic in Norway with Experiences from the UK and Denmark

\author{
Hertzum, Morten; Ellingsen, Gunnar
}

Published in:

International Journal of Medical Informatics

DOI:

10.1016/j.ijmedinf.2019.06.026

Publication date:

2019

Document version

Peer reviewed version

Document license:

CC BY-NC-ND

Citation for published version (APA):

Hertzum, M., \& Ellingsen, G. (2019). The Implementation of an Electronic Health Record: Comparing

Preparations for Epic in Norway with Experiences from the UK and Denmark. International Journal of Medical Informatics, 129, 312-317. https://doi.org/10.1016/j.ijmedinf.2019.06.026 


\title{
The Implementation of an Electronic Health Record: Comparing Preparations for Epic in Norway with Experiences from the UK and Denmark
}

\author{
Morten Hertzum \\ Department of Information Studies, University of Copenhagen, Copenhagen, Denmark \\ Gunnar Ellingsen \\ Institute of Clinical Medicine, UIT - The Arctic University of Norway, Tromsø, Norway
}

\begin{abstract}
Background - The implementation of electronic health records (EHRs) requires careful preparations but may still cause trouble. In this study we focus on one EHR - Epic.

Purpose - We compare the experiences from implementing Epic in the UK and Denmark with the preparations for implementing it in Norway.

Method - The study is based on document analysis (UK and Denmark) and interviews (Norway).

Results - Epic had a troubled start in both the UK and Denmark with malfunctions in the interfaces to other clinical systems, disruptions in the continuity of care, and drops in performance. While the state of routine use has subsequently been reached in the UK, the transition process is still ongoing in Denmark. In Norway experiences from, especially, Denmark are heeded in planning the implementation of Epic, which is expected to deliver better care more efficiently. We discuss six pitfalls to achieving these benefits.

Conclusion - Experiences from, especially, Denmark inform the Norwegian preparations, but these experiences point toward more challenges than solutions. The implementation of Epic in Norway is currently in a state of considerable uncertainty.
\end{abstract}

Keywords: electronic health records, adoption, implementation.

\section{Introduction}

Electronic health records (EHRs) are complex systems with direct effects on the documentation and coordination of care and indirect effects on process efficiency, quality of care, staff satisfaction, and hospital finances. In addition, EHRs are increasingly integrated, that is, they connect and require alignment among departments, specialties, staff groups, work processes, and so forth. To achieve this integration EHRs include many facilities. Thus, the functionality of one EHR corresponds to that of many paper records and legacy systems. The complexity and integration make it a major investment and daunting task for a hospital to implement an EHR [1,2]. In this study we focus on one EHR Epic - and compare three cases that are at different stages in the implementation process.

Epic is an integrated suite of software with functionality ranging from patient administration, through systems for physicians, nurses, pharmacists, radiologists, lab technologist, and other care providers, to billing systems, integration to the primary health sector, and a facility for granting patients access to their own data. Being originally developed for the US market, Epic has only recently been implemented in Europe. Our cases are from three European countries. In the UK, Epic went live at Cambridge University Hospitals in October 2014 and after a troubled start they have reached the state 
of routine use. In Denmark, Epic went live at Herlev and Gentofte Hospital in May 2016 and two years later the transition is still ongoing. In Norway, the Health Platform program in Central Norway is responsible for the procurement and implementation of Epic. The implementation is planned to start in 2021. We contend that these three cases are illustrative, in particular the implementation in the UK was the first Epic implementation in Europe and the implementation in Denmark is the primary source of learning for the implementation in Norway. However, we acknowledge that Epic has been implemented in additional European countries.

While any implementation is shaped by the particulars of the local context [3], experiences from existing Epic implementations provide insights valuable to the research community and to hospitals contemplating to implement Epic. A concrete motivation for the present study is to inform the preparations of the upcoming Epic implementation in Norway. We specifically ask:

- How did the hospitals prepare for go-live and how did the UK and Danish experiences after golive match their expectations?

- How did experiences from previous Epic implementations, such as those in the UK and Denmark, inform the Norwegian preparations?

It is generally recognized that the period immediately following the go-live of an EHR is stressful and associated with a productivity dip. Priestman et al. [1] find that, depending on the productivity parameter, it normally takes 6-12 months to return to baseline productivity. For Epic the stress level at go-live is further increased by the big-bang implementation strategy endorsed by the Epic company. The longer-term benefits of EHRs include better documentation, fewer medical errors, and improved interdisciplinary collaboration [1]. However, these benefits are often accompanied by an increase in the amount of time spent on documentation, especially by physicians [4]. This increase is contrary to their wishes because physicians already spend a substantial amount of their time on documentation [5] and would like to spend less time on documentation in order to have more face time with patients [6].

\section{Method}

We answer the research questions through document analysis and interviews. Projects the size of Epic implementations are subject to scrutiny from health authorities, which document their assessments in reports. Such reports form the main input for our analyses of the UK [7, 8] and Danish [9] cases. In addition, selected project documents are publicly available from the Danish $[10,11,12]$ and Norwegian [13] cases. For the Norwegian case we have also interviewed six representatives of top management in the Health Platform program. These interviews, conducted in October to December 2018, focused on potentials and challenges with Epic and also included reflections on the Epic implementation in Denmark. Given the top-management interviewees, the interviews were conducted in an open-ended manner, which provided the interviewees with the opportunity to organize their answers within their own frameworks [14]. We contend that this increased the validity of the responses.

The interviews were audio-recorded, transcribed, and analyzed by identifying common themes across the interviewees and by contrasting interviewee statements with the findings from the UK and Danish cases. In quotes, the interviewed managers are denoted Manager-1, Manager-2 and so forth where the numbers indicate the order in which they are quoted in the text for the first time. For all three cases, media coverage provides supplementary input.

\section{The UK Case: Cambridge University Hospitals}

Epic went live at Cambridge University Hospitals (CUH) on October 26, 2014, eighteen months after the contract between CUH and Epic was signed. The contract amounted to $£ 200$ million (EUR 275 million) and involved the implementation of Epic all across CUH, which had 1486 beds, 8930 staff (in full-time equivalents), and an outpatient attendance (July 2014 - June 2015) of 1,336,900 [8]. Prior to the Epic implementation CUH was minimally digital; it had received a rating of Stage 1 on the Electronic Medical Record Adoption Model (EMRAM), whose stages range from 0 to 7 [15]. That is, 
some ancillary systems were digital but all other records were paper-based. The vision for Epic was to replace paper records with one integrated electronic health record that spanned all clinical areas, including intensive care, anesthesia, and the laboratories. As a consequence, the implementation of Epic included the installation of about 6750 personal computers, 500 laptops, and 395 workstations on wheels. In addition, the implementation entailed the training of about 12000 staff.

The implementation followed the big-bang approach endorsed by Epic, that is, CUH went live all at once rather than in phases. In the period immediately after go-live CUH experienced a number of problems $[15,16]$ :

- Incomplete access to patients' medical history because the paper-to-Epic transfer had not been completed.

- Disruption to pathology services caused by problems with specimen label printers.

- A four-hour period of unplanned downtime requiring the diversion of all ambulances to other hospitals.

- Problems with the delivery of pathology test results, leading to difficulties in matching results to patients.

- A several-day period of instability of one of the transfusion system interfaces.

- Disruptions in the consistency of care, including venous thromboembolism assessments, nursing care plans, and the completion of discharge summaries.

- A $20 \%$ drop in emergency department performance and large productivity decreases in outpatient clinics.

Six months after go-live (in April 2015) the Care Quality Commission carried out an inspection of CUH. The inspection report [7] rated CUH services "inadequate" on four out of six parameters: overall, safety, responsiveness, and well-ledness. With respect to effectiveness CUH services received a "requires improvement" rating. The only positive rating was a rating of "outstanding" with respect to whether services were caring. While staff shortages contributed to the inadequacies, the report also explicitly mentioned Epic as a contributor:

- Epic was beginning to be embedded into practice but it was "still having an impact on patient care and relationships with external professionals" [7, p. 3].

- Limitations in Epic meant that medicines were not always prescribed correctly.

- Problems with Epic made it difficult for staff to follow required guidelines.

- Although CUH participated in most audits, Epic had made it more difficult to collect audit data.

- Epic had negatively affected CUH's ability to "report, highlight and take action on data" [7, p. 3].

The cost of the Epic implementation also contributed to an overspending of about $£ 1.2$ million a week. As a result of the inspection and the financial difficulties, CUH was placed in special measures in September 2015 and its chief executive had to resign [17]. In motivating these steps it was argued that in some of CUH's services "patient safety and welfare was placed at risk" $[17, p .1]$. That is, about a year after go-live CUH was experiencing multiple and severe difficulties, rather than reaping benefits from its Epic implementation.

The Care Quality Commission carried out a second inspection at CUH in September 2016 [8], about two years after Epic went live. At this point CUH services had improved to a rating of "good", except with respect to responsiveness, which was rated as "requires improvement". With explicit reference to Epic the inspection report stated that:

"Records were contemporaneous and complete. Staff had easy access to clinical records. Since our last inspection a significant number of modifications had been made to the electronic record system and concerns we had raised previously had been addressed." [8, p. 7] 
The improvements were partly due to CUH staff's increased familiarity with Epic but also included the integration of all patient administrative and clinical information. With Epic the paper records were eliminated and, thus, no longer had to be retrieved whenever they were needed. This elimination alone saved CUH an estimated $£ 460,000$ a year in staff time [15]. Furthermore, all patients wore barcoded wristbands linked to Epic, thereby improving patient safety by reducing the risk of misidentification. In total, Epic and the initiatives associated with it had moved CUH to Stage 6 on EMRAM [15].

\section{The Danish Case: Herlev and Gentofte Hospital}

Epic went live at Herlev and Gentofte Hospital (HGH) on May 21, 2016. The implementation was the first in a series of implementations that rolled out Epic at all hospitals in two of the five healthcare regions in Denmark. The implementation of Epic at HGH followed the big-bang approach, and so did the implementations at the other hospitals in the two regions. In-between these big-bang implementations there were periods for learning and adjustments. The last hospitals in the roll-out started to use Epic in November 2017. The contract for the full implementation in the two regions was signed in December 2013 and amounted to DKK 2.8 billion (EUR 375 million), thereby making it the largest IT investment in Danish healthcare [9]. We analyze the implementation of Epic at the first hospital in the series of implementations, HGH.

HGH had 949 beds, 6449 staff, and an annual outpatient attendance of about 742,600. Prior to the implementation of Epic it was estimated that HGH was at Stage 3 on EMRAM [11]. That is, ancillary systems (most notably the laboratory and radiology systems) were digital and fed data to a clinical data repository, which also included most nursing documentation; the remaining records were a mix of paper forms and digital systems. The vision for Epic was to eliminate paper records and replace many existing clinical information systems with one integrated electronic health record [10]. In Epic this included the intensive-care and anesthetics module as well as the medicine module. In addition, integrations to the above-mentioned ancillary systems were established. It was expected that the main benefits of Epic would be more efficient patient administration and clinical processes. To achieve these benefits Epic had to be adjusted to match the Danish healthcare context. These adjustments involved changes in the user interface as well as the underlying functionality.

HGH experienced a number of problems after go-live. A status report in August 2016 compiled the problems that had transpired during the first three month with Epic [12]:

- The number of adverse events and incidents at HGH increased after go-live; in two cases patients suffered injury as a result of Epic.

- Referrals, admission reports, discharge reports, and epicrises were not sent correctly due to technical problems.

- The identity of unnamed newborn babies was difficult to establish because they appeared as 'Unknown', that is, without their mother's social security number.

- The Epic displays in the emergency department caused problems for the staff, who had difficulty gaining an overview of the patients and their status.

- The integration between Epic and some of the medical equipment malfunctioned, so data were not transferred from the equipment to the patients' records in Epic.

- The integration with the national medicine chart had errors, such as occasional duplication of medical orders, thereby creating uncertainty and workarounds.

- Many blood-test orders remained unsent because they did not comply with new requirements to their content, often without the physicians understanding why the order had not been sent or even realizing it.

Problems continued over the following months. As a result the implementation process was assessed by Rigsrevisionen, an independent auditing institution under the Danish Parliament, in a report in June 2018. The report [9] criticized the training, testing, benefits estimation, and benefits follow-up: 
Training in the use of Epic started two weeks later than planned, that is, six weeks before go-live. The compressed schedule was caused by the delayed completion of training materials and, in turn, caused problems completing the training of all staff. The training materials were delayed by adjustments to Epic. In the end, adjustments to Epic continued after training had started and many users received training in a training environment dissimilar from the system they met at go-live. In a small survey a month after go-live only one of the 149 respondents felt adequately prepared for starting to use Epic; the pre-set target level was $80 \%$ [9].

The testing of Epic also started later than planned. Critical technical tests were not made until a week before go-live because the features to be tested were delayed. The tests were complicated by known errors that had not yet been fixed and they identified new errors, including 20 in the categories critical and severe. These 20 errors were not fixed until after go-live. Specifically, the test of whether Epic produced the same data for reimbursement as the old systems was conducted the day before go-live and revealed problems; it was decided not to compare the data produced by Epic with those from the old systems. In addition, the functional test of whether Epic fulfilled the specified requirements was postponed until October, five months after go-live. That is, at go-live HGH had incomplete knowledge about defects. When conducted the functional test revealed 196 defects [9].

The benefits estimation in the business case [10] concluded that the financial benefits of Epic would surpass the investment no later than in 2022. Central to this estimate was an expectation that the productivity dip after go-live would only last three weeks [9]: 50\% during the first two weeks and $25 \%$ during the third week. The basis for this optimistic expectation is unclear, for example a draft version of the business case [11] predicted a productivity dip for the remainder of the year in which Epic went live. Possibly, the estimated three-week productivity dip was partly a strategic decision to maintain pressure on $\mathrm{HGH}$ to return to baseline productivity. As much as 18 months after go-live productivity had not yet returned to baseline [9].

Benefits follow-up was put on hold in May 2017 due to defects in the facilities for extracting follow-up data from Epic. These report facilities was an area that received limited focus during testing and it was subsequently (September 2017) necessary to suspend nearly half of the 750 reports because they had turned out to be invalid in a Danish healthcare context [9]. In addition, data about the baseline productivity were not available for 20 of the 26 productivity measures identified for follow-up. At the time of Rigsrevisionen's assessment, two years after go-live, it remained uncertain to what extent productivity was still lagging behind baseline and to what extent the lag was an artifact of imprecise follow-up data [9]. Epic had not yet transitioned from stressful implementation to effective and efficient routine use.

\section{The Norwegian Case: The Health Platform}

The Health Platform is a regional program owned by the Central Norway Regional Health Authority and Trondheim municipality. It aims to acquire and implement Epic for the whole region, including all the hospitals, general practitioners (GPs), nursing homes, and home-care services. By including the municipalities, the health authorities want to stage the Health Platform as a pilot for the long-term national goal of establishing a common EHR functionality for Norway across the different regions and services, "one citizen - one record" [18].

The Central Norway region includes 40,000 healthcare professionals and an approximate population of 720,000 . There are 3 hospitals whereof the largest is the university hospital, St Olav's Hospital, located in Trondheim with approximately 1000 beds and 10,500 employees. St Olav's Hospital is already at a high level of digitization but many of the existing laboratory systems will be replaced by Epic's laboratory system (except pathology and medical genetics, which will require integration). In addition, the intensive-care and anesthetics module and the medicine module will be implemented. The level of digitization varies substantially across the GPs, nursing homes, and home-care services, where particularly the GPs already have well-working systems at their disposal. The cost of the program amounts to NOK 2.7 billion (EUR 270 million) [19]. 
Out of 11 prequalified EHR vendors in 2016, Epic is now left as the only contender. Negotiations are currently under way on what the solution should consist of and on how to proceed with the implementation. The signing of the contract is planned for 2019 and the first implementation for 2021. Trondheim municipality will be in the first implementation, while the rest of the 84 municipalities in Central Norway have the option to buy in to the solution after that.

According to Manager-1 the preparation process for "mapping of integrations, migration work and standardization" has been more thorough than what has proven to be the case in Denmark. Moreover, from early on, extensive user participation has been identified as crucial to the success of the program, both for creating ownership to Epic and for ensuring a well-working functionality. This was underscored by one of the managers:

"When we started the acquisition project, we involved 400 clinicians from the entire healthcare service in Central Norway, small and large municipalities and hospitals [...] They participated in 101 workshops and described what was good with the current ICT systems, their current challenges, and what was missing" (Manager-2)

The outcome of these workshops became the basis for the requirements specification, which included 4000 specific requirements.

Another crucial point in the preparations is to ensure that the municipalities buy in to the Epic solution as early as possible in order to create stability and predictability around the solution. The managers recognize the municipalities' point of view and that it is different from that of the hospitals:

"A challenge is that the program is very hospital-run. It is the Central Norway Regional Health Authority that owns the program. Even if Trondheim municipality participates, the main effort is to acquire an EHR for Central Norway, and we feel that we must ensure that the municipalities are taken into account" (Manager-3)

A strategy for accommodating the needs of the municipalities has been to involve their user representatives in the acquisition process. The purpose of this involvement has been to assure these representatives that Epic can be adapted to the needs of the various user groups in the municipalities. A recent arrangement with the Norwegian state ensures that each of the municipalities may finance the investment costs through a loan from the Norwegian Government.

So far, the negotiations between the Health Platform and Epic have been promising:

"We had a very thorough dialogue with Epic in the spring of 2018. In this period, we experienced that they really improved their understanding of what we wanted. In this situation, we also experienced that they brought with them know-how and knowledge from Denmark and Finland that was useful in Norway" (Manager-4)

Like in the Danish case, designated clinicians are supposed to be heavily engaged in configuring Epic, that is, in designing functionality for their practice. In the Epic world, these clinicians are called "physician builders" and reflect the promise of future work processes in which the technology is closely embedded in clinical practices. The physician builders are to take part in configuring the initial Epic setup and in a subsequent regional organization that should continue to work on optimizing and streamlining key work processes. The physician builders will have these activities as their full-time work. In addition, so-called clinical builders (a kind of super users) will be recruited to work part-time with Epic together with their clinical work. User participation in general and physician/clinical builders in particular are considered crucial in the startup phase. An essential reason for this is the rigid way in which Epic runs implementation projects:

"They have a very rigid and tight project plan. They have the philosophy of: let's just get the solution up and running and let's build the capability in the organization to understand the solution and its possibilities" (Manager-5)

In this process, it is of utmost importance that the customer has available resources that can take part in the process and decision-makers that can make decisions on what the configured system shall look like. According to Epic policies these decisions must typically be made within a 10-day deadline. If the customer fails to meet the deadline, Epic will set up the system with the "foundation" functionality, that is, with the default functionality that appears to be the best fit to the current situation.

The Health Platform managers express that the user communities in Denmark were only involved in the implementation process to a lesser degree and that there was to a lesser degree an established 
decision structure, that is, people with a mandate from the line organization to make decisions. This resulted in what the Health Platform managers refer to as a "consensus model". Accordingly, many decisions were delayed and Epic, therefore, defaulted to the foundation setup in these areas. Another lesson learned is that a tailored Epic system depends on the involvement of various types of technical analysts and physician builders in the setup phase. They are actually building the system. The tight schedule, an absent decision or an unforeseen workload may prevent the builders from completing their work on time. The Health Platform is working hard to ensure that these problems do not happen in Norway:

"Now we are in the process of establishing a decision structure [...] that is, involve people from the line organizations who can contribute to responding to all the questions that need to be responded to on a very short notice [10 days]. Epic will probably raise something like 8000-12000 questions when they start the implementation" (Manager-2).

After the implementation, the physician builders and analysts are supposed to continue improving and optimizing Epic, while the vendor will be involved to a lesser extent.

The Health Platform expects many long-term effects from the program, particularly related to a healthcare service that is better integrated within the hospital and among the hospitals, municipalities and GPs. This also includes the standardization of work processes and will require some disciplining of the clinicians in their daily use of Epic. This disciplining might constitute a serious challenge. The Health Platform works to handle this challenge by informing the line organizations about how practices will be affected. Overall, the long-term effects are first and foremost related to quality improvements. In comparison to the Danish case, the Health Platform has no business case that promotes concrete economic gains. Still, there exist internal calculations on potential economic effects that might occur if things go as planned.

\section{Discussion}

The period after Epic went live was wrought with problems in the UK and Denmark. In the UK it took roughly the 6-12 months estimated by Priestman et al. [1] before productivity had returned to baseline. In Denmark it had not yet happened after 18 months, in spite of the expectation that the productivity dip would last for only three weeks. For many months both CUH and HGH experienced disruptions in the continuity of care due to, among other things, malfunctions in the interfaces between Epic and other clinical systems. At HGH training and testing were severely incomplete at go-live. Nevertheless, $\mathrm{CUH}$ and HGH chose against delaying go-live. In Norway the preparations aim to ensure a smoother implementation process but several points are worth noting:

First, the organizational complexity of the Norwegian case is higher than that of the UK and Danish cases, which are restricted to hospitals. In Norway, Epic will be implemented throughout a region, that is, in its hospitals as well as in the GP clinics, nursing homes, and home-care services of its 84 municipalities. In total, this represents several hundred sites. While the inclusion of the municipalities may increase the possibilities for streamlining and transforming regional healthcare, it also makes the users more heterogeneous and the implementation more challenging to manage.

Second, the organization set up to conduct the implementation is in an uneasy position between Epic and the clinicians. The interviewed Norwegian top managers appear somewhat worried by the tight deadlines enforced by Epic. At the same time they emphasize the importance of widespread user participation to create ownership and get the functionality right. This double pressure on the implementation organization leaves little room for it to be proactive and may create the kind of environment that leads to compressed training schedules, postponed testing, and frustrated staff.

Third, the Norwegian case relies on the creation of an extensive formal decision structure with a strong foothold among the clinicians. This decision structure is expected to curb the risk associated with the big-bang implementation of Epic. While the need for such a decision structure appears to be one of the key lessons the Norwegians draw from the Danish case, this decision structure has yet to be created and may remain wavery. At the same time it is not evident that a more formal decision 
structure would have improved matters in the Danish case; some Danish clinicians find that the decision structure has been too top-down - too inattentive to local voices.

Fourth, similar to the Danish case, it is crucial that Epic can be adapted to the Norwegian healthcare context. This requires the recruitment of a large number of clinicians who are committed to this kind of work. In Denmark, a team of 70 physician builders is already considered insufficient. A potential challenge in recruiting physicians is that their clinical career path is relatively fixed and does not include IT. While a new type of profession may be established in this area as suggested by one of the Norwegian top managers, physicians have historically not participated extensively in large-scale EHR projects [20]. The prestige of such a new profession may, however, increase with the strengthened medical focus on IT, illustrated by the introduction of chief medical informatics officers (CMIOs).

Fifth, the UK and Danish cases demonstrate that the need for configurations and adaptations does not end at go-live. However, far-reaching decisions about the standardization of routines and processes have to be reached in a complex decision structure and implemented before go-live. It is an open question to what extent it will be practically possible to make larger configurations once these decisions have been made. While Epic is promoted as a flexible platform, the setup with many initial, far-reaching regional decisions may "freeze" practices and technology in a way that makes them hard to change later. One step toward such an outcome is seen in the Danish case where the physician builders have had less freedom to configure Epic than they initial expected because such freedom is at odds with overall standardization strategy.

Finally, the benefits estimation in the Danish case has been sharply criticized by Rigsrevisionen. This criticism has not gone unnoticed in the Health Platform program, and a lesson learned from this appears to be that the Norwegians are careful not to promote measurable benefits related to economy and efficiency at this stage in the project. Instead, the promoted benefits relate to higher treatment quality and better coordination between hospital care and municipal care.

\section{Conclusion}

Judging from the UK and Danish cases, the implementation of Epic in Norway will be a challenge. Experiences from, especially, the Danish case appear to have considerable influence on the Norwegian Health Platform program. However, these experiences identify more challenges than solutions and the preparations for the Norwegian implementation of Epic is therefore currently in a state of considerable uncertainty. In future work we will continue to compare European implementations of Epic.

\section{Authors' contributions}

The first author conceived the study, collected the material about the UK and Danish cases, and drafted the analyses of these cases. The second author conducted the interviews about the Norwegian case and drafted the analysis of this case. Both authors contributed to the discussion as well as critically revised and approved the entire manuscript.

\section{Acknowledgements}

This study has not received external funding.

\section{Statement on conflicts of interest}

The authors are unrelated to Epic and have no conflicts of interest to declare.

\section{Summary table}

What was already known about the topic:

- The implementation of electronic health records requires careful preparations

- Previous implementation experiences are valuable sources of learning 
- Big-bang implementations are risky but preferred by vendors such as Epic

What this study added to our knowledge:

- The documented experiences from the UK and Danish implementations of Epic identify more challenges than solutions and are therefore not straightforward to learn from

- The Norwegian preparations are in a state of considerable uncertainty, caused by high complexity, double pressures, and the need for simultaneously adapting Epic and many clinical work processes

\section{References}

[1] W. Priestman, S. Sridharan, H. Vigne, R. Collins, L. Seamer, N.J. Sebire, What to expect from electronic patient record system implementation: Lessons learned from published evidence, Journal of Innovation in Health Informatics 25, 2 (2018) 92-104.

[2] J. Ross, F. Stevenson, R. Lau, E. Murray, Factors that influence the implementation of e-health: A systematic review of systematic reviews (an update), Implementation Science 11 (2016) article 146.

[3] J. Simonsen, C. Svabo, S.M. Strandvad, K. Samson, M. Hertzum, O.E. Hansen (Eds.), Situated design methods, MIT Press, Cambridge, MA, 2014.

[4] L. Poissant, J. Pereira, R. Tamblyn, Y. Kawasumi, The impact of electronic health records on time efficiency of physicians and nurses: A systematic review, Journal of the American Medical Informatics Association 12, 5 (2005) 505-516.

[5] C. Sinsky, L. Colligan, L. Li, M. Prgomet, S. Reynolds, L. Goeders, J. Westbrook, M. Tutty, G. Blike, Allocation of physician time in ambulatory practice: A time and motion study in 4 specialties, Annals of Internal Medicine 165, 11 (2016) 753-760.

[6] E. Joukes, N.F. De Keizer, A. Abu-Hanna, M. de Bruijne, R. Cornet, End-user experiences and expectations regarding data registration and reuse before the implementation of a (new) electronic health record: A case study in two university hospitals, in: MEDINFO2015 Proceedings, IOS Press, 2015, p. 997.

[7] CQC, Cambridge university hospitals NHS foundation trust: Quality report, 22. Sept. 2015, Care Quality Commission, London, 2015.

[8] CQC, Cambridge university hospitals NHS foundation trust: Quality report, 18. Jan. 2017, Care Quality Commission, London, 2017.

[9] Rigsrevisionen, Beretning om sundhedsplatformen, The Danish Parliament, Copenhagen, 2018.

[10]Capital Region of Denmark, Region Hovedstadens business case ved Sundhedsplatformen, version 2.4.4, Capital Region of Denmark, Copenhagen, 2015.

[11]Capital Region of Denmark, Business case for it-sundhedsplatformen for Region Hovedstaden, version 1, Capital Region of Denmark, Copenhagen, 2012.

[12]Capital Region of Denmark, Sundhedsplatformen: Statusrapport til styrelsen for patientsikkerhed, 12. august 2016, Capital Region of Denmark, Copenhagen, 2016.

[13]Central Norway Regional Health Authority, Helseplattformen - Én journal for hele helsetjenesten i Midt-Norge. https://helse-midt.no/vart-oppdrag/prosjekter/ehelse/helseplattformen (accessed Oct $28,2018)$.

[14]J.D. Aberbach, B.A. Rockman, Conducting and coding elite interviews, PS: Political Science \& Politics 35, 4 (2002) 673-676.

[15]National Advisory Group on Health Information Technology in England, Making IT work: Harnessing the power of health information technology to improve care in England, Department of Health, London, 2016.

[16]A. O'Dowd, New e-records system leads to $20 \%$ drop in emergency department performance at Addenbrooke's, BMJ 349 (2014) article g7537.

[17]M. Limb, Addenbrooke's ordered to improve after "inadequate" rating, BMJ 351 (2015) article h5066.

[18]Direktoratet for e-helse, Utviklingstrekk 2018 - Beskrivelser av drivere og trender relevant for ehelse. Versjon 1.0, Oslo, Norway, 2018. 
[19]Dagens Medisin, Ute av dansen i kampen om IT-kontrakt verdt 2,7 milliarder.

https://www.dagensmedisin.no/artikler/2016/11/25/ute-av-dansen-i-kampen-om-it-kontrakt-verdt27-milliarder/ (accessed Oct 30, 2018).

[20]L. Silsand, G. Ellingsen, Generification by translation: Designing generic systems in context of the local, Journal of the Association for Information Systems 15, 4 (2014) 177-196. 